\title{
Rádios comunitárias e epistemologias do Sul: a constituição de estratégias para a mobilização social
}

\section{Community Radios and South Epistemologies: The constitution of strategies to social mobilization}

\author{
Maria Ivete Trevisan Fossá ${ }^{l}$ \\ (fossa@terra.com.br) \\ Kalliandra Quevedo Conrad ${ }^{2}$ \\ (kalliandraconrad@gmail.com) \\ http://dx.doi.org/10.5216/cei.v15i2.24567
}

\begin{abstract}
Resumo
Este trabalho, de caráter teórico-empírico, busca compreender de que forma as rádios comunitárias constituem-se como uma estratégia para a mobilização social. Os objetivos pretendidos são: discutir os conceitos de mídia alternativa, comunicação comunitária e seus desdobramentos; e aproximar os conceitos de rádio comunitária das ecologias propostas por Santos (2007). Ao final, a fim de elucidar essa aproximação, verificamos, em uma das rádios comunitárias da cidade de Santa Maria (RS), como essa relação conceitual se manifesta. Essas ecologias são entendidas como estratégias comunicacionais para a mobilização social empreendidas em um contexto de inclusão social e de exercício da cidadania.
\end{abstract}

Palavras-chave: Rádios comunitárias. Mobilização social. Ecologia dos saberes.

\begin{abstract}
This work, from theoretical-empirical approach, seeks to understand how community radios constitute themselves as a strategy to social mobilization. The objectives are: discuss the concept of alternative media, community communication and its unfolding; and to approach the concepts of community radios to proposed ecologies by Santos (2007). By the end, in order to elucidate this approach, we verified, in one of the community radios in the city of Santa Maria (RS), as this conceptual relation manifests itself. These ecologies are understood as communication strategies to social mobilization taken in to a context of social inclusion and citizenship exercise.
\end{abstract}

Keywords: Community Radios. Social Mobilization. Ecology of Knowledge.

\section{Introdução}

O presente trabalho estrutura-se em duas etapas. A primeira compreende a discussão teórica acerca dos conceitos de mídia alternativa, comunicação comunitária e seus desdobramentos. Em um

\footnotetext{
${ }^{1}$ Possui graduação em Comunicação Social - Habilitação em Relações Públicas e Administração, pela Universidade Federal de Santa Maria, mestrado em Comunicação Social pela Universidade Metodista de São Paulo e doutorado em Administração pela Universidade Federal do Rio Grande do Sul. Atualmente é professora adjunta da UFSM. Brasil, Santa Maria.

${ }^{2}$ Possui graduação em Comunicação Social - Relações Públicas pela UFSM. Atualmente é mestranda em Comunicação Midiática do Programa de Pós Graduação da UFSM, atuando na linha Mídia e Estratégias Comunicacionais. Brasil, Santa Maria.
}

Comun. \& Inf., v. 15, n. 2, p. 34-52, jul./dez. 2012 
segundo momento, refletimos sobre os conceitos fundamentes da teoria da epistemologia do sul. Na segunda etapa, empreendemos uma análise empírica com uma das rádios comunitárias da cidade de Santa Maria (RS).

O embasamento teórico apoia-se em autores como Carpentier, Lie e Servaes (2001) para o conceito de mídia alternativa e, principalmente, em Peruzzo $(2006 ; 2009 ; 2012)$ para o conceito de comunicação comunitária. Nosso intuito de renovar o olhar sobre a mídia e reinventar as rádios comunitárias fundamenta-se no pensamento de Santos (2007; 2009).

Nosso esforço teórico-empírico objetiva pensar as rádios comunitárias como uma estratégia para a mobilização social a partir da relação aproximativa entre as rádios comunitárias e as ecologias de Santos (2007). Para visualizar as ecologias empiricamente, verificamos, por meio de entrevista semiestruturada, com um representante da rádio comunitária Cidadania FM, as possíveis aproximações.

\section{De qual comunicação estamos falando?}

O conceito de comunicação comunitária carrega em si uma marca ideológica (MIANI, 2006) que não pode ser ignorada. Da mesma forma, o conceito de mídia comunitária merece esclarecimentos que possam contribuir para o desenvolvimento da reflexão em torno das estratégias comunicacionais para a mobilização social. Pretendemos, dessa forma, apresentar possibilidades de compreensão das rádios comunitárias a partir do pensamento de Carpentier, Lie e Servaes (2001).

Os autores trazem o conceito de mídia alternativa sob quatro abordagens: (I) a mídia alternativa que atende à comunidade; (II) a mídia alternativa que é uma alternativa aos meios de comunicação hegemônicos; (III) a mídia alternativa como parte da sociedade civil e (IV) a mídia alternativa como um rizoma. Essas abordagens se subdividem em dois blocos distintos. Um deles compreende a visão essencialista das mídias alternativas e, a outra, a visão relacionista. Ambas, desmembram-se na definição da identidade das mídias alternativas e no espaço que ocupam na sociedade. A partir disso, os autores elaboraram uma tabela que adaptamos (Tabela 1) para nos auxiliar na compreensão das rádios comunitárias nessa teia de conceitos e abordagens.

Tabela 1 - posicionamento das quatro abordagens teóricas

Comun. \& Inf., v. 15, n. 2, p. 34-52, jul./dez. 2012 


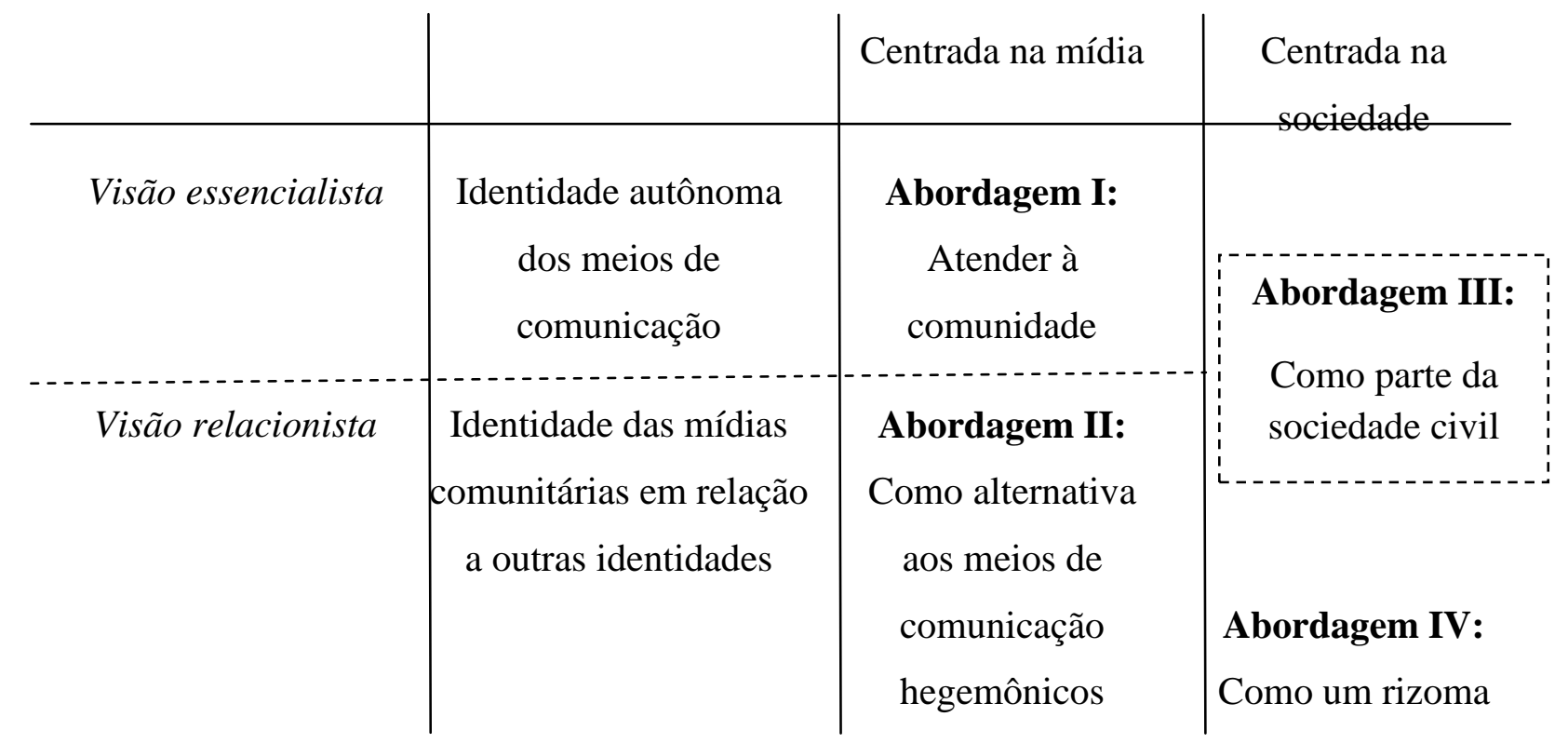

Fonte: Carpentier, Lie e Servaes (2001).

A orientação essencialista define as mídias comunitárias em si mesmas, o que, no nosso entendimento, individualiza e retira essa mídia de seu contexto. Entretanto, a orientação relacionista confronta as mídias comunitárias com sua trama cultural, política, econômica, histórica e social. Sua identidade é definida numa relação de alteridade, em que se reconhece o outro para reconhecerse a si mesmo.

Primeiramente, precisamos definir o que é uma mídia alternativa. A mídia a que estamos nos referindo seria alternativa ao que Carpentier, Lie e Servaes (2001) nomeiam de mainstream ou grande mídia/mídia hegemônica. A mídia hegemônica é aquela que produz em larga escala, tem como foco principal a comercialização de propaganda e pode ser privada ou estatal. Sua estrutura é hierárquica e obedece às lógicas de manutenção do status quo da racionalidade instrumental do modo de produção capitalista. Seu discurso dominante representa a voz uníssona do monopólio midiático brasileiro.

As mídias alternativas, por outro lado, produzem para um nível local, pois são direcionadas a uma comunidade específica (Abordagem I). Representam uma opção comunicacional e democrática frente aos meios de comunicação hegemônicos (Abordagem II). Ambas as abordagens se interrelacionam mutuamente, visto que, uma mídia pode ser alternativa aos meios de comunicação hegemônicos e também atender à comunidade local. Acionamos nesta perspectiva o 
conceito de mídia comunitária para designar a combinação de uma mídia que é alternativa e que atende às necessidades de informação de uma comunidade específica.

As abordagens III e IV representam, respectivamente, a mídia alternativa na sociedade. A terceira abordagem considera a mídia alternativa situada entre a mídia que pertence ao Estado e à mídia que pertence ao mercado. Os autores argumentam que essa abordagem é fundamental para a viabilidade da democracia através da mídia. Na última abordagem, a mídia alternativa atua como catalizadora nos processos de luta política das minorias e dos movimentos sociais. Funciona como um instrumento social para dar voz e também como um meio que rearticula organizações e movimentos da sociedade civil, numa perspectiva rizomática.

A partir dessas anotações sobre o conceito de mídia alternativa, pretendemos discutir sobre qual comunicação compete a esse tipo de mídia. Nos apoiamos, principalmente, nos aportes teóricos de Peruzzo $(2006 ; 2009 ; 2012)$ para problematizarmos este conceito.

De acordo com Peruzzo (2012) há quatro concepções de desenvolvimento: econômico, participativo, integral e sustentável. O desenvolvimento econômico representa os interesses do capital, visando à exploração através do lucro. Busca dar prioridade à industrialização e às grandes empresas em detrimento da valorização da economia local. O desenvolvimento participativo pressupõe a participação dos sujeitos na organização e na tomada de decisões com vistas a superar os antagonismos de classe. "[...] tem a ver com participação, integração, sustentabilidade e igualdade, no sentido de proporcionar retorno dos benefícios a todas as pessoas" (PERUZZO, 2012, p. 8). O desenvolvimento integral proporciona o desenvolvimento dos sujeitos em todas as suas dimensões, desde sua consciência política, gestão, geração de conhecimento e cognição. E o desenvolvimento sustentável está relacionado ao respeito à cultura e no uso responsável dos recursos naturais.

Como um contraponto ao desenvolvimento econômico, os desenvolvimentos participativo, integral e sustentável mantém um mesmo eixo aproximativo vinculado à cidadania. Da mesma forma, no processo comunicativo das rádios comunitárias emergem novas formas de desenvolver a sociedade através da participação dos sujeitos na discussão e deliberação acerca de assuntos de interesse coletivo (desenvolvimento participativo), no desenvolvimento social, cultural e político dos sujeitos (desenvolvimento integral) e no respeito à cultura local e suas formas de convivência homem-natureza (desenvolvimento sustentável), propiciando condições para pensarmos as rádios comunitárias em um contexto de desenvolvimento que incentive práticas democráticas de produção, consumo e disseminação da informação e da comunicação.

Comun. \& Inf., v. 15, n. 2, p. 34-52, jul./dez. 2012 
É no contexto dos desenvolvimentos participativo, integral e sustentável que se inserem as rádios comunitárias: como uma mídia que integra à comunidade para transformá-la. Abre possibilidades de resgatar os valores comunitários que são produzidos através dos processos de participação e inclusão comunicativa. Apresentam-se como uma ruptura ao monopólio da fala mantido pelos meios de comunicação hegemônicos. Dessa forma, o movimento pela democratização da comunicação surge nesse cenário como um processo capaz de promover a democratização da comunicação. Em relação a este processo de democratização, discutiremos as diferentes conceituações em torno do conceito de comunicação comunitária.

Segundo Peruzzo (2009), as comunicações popular, alternativa e comunitária podem ser diferenciadas, visto que, a comunicação popular é a comunicação feita pelo povo e para o povo; a comunicação alternativa é a comunicação alternativa aos meios de comunicação hegemônicos e a comunicação comunitária é a comunicação como um direito do cidadão que visa a democratização da comunicação. As diferentes terminologias compreendem um mesmo sentido para a comunicação comunitária, sendo que esta também é uma forma de comunicação popular e alternativa.

Em síntese, a comunicação popular, alternativa e comunitária se caracteriza como expressão das lutas populares por melhores condições de vida que ocorrem a partir dos movimentos populares e representam um espaço de participação democrática do 'povo'. Possui conteúdo crítico-emancipador e reivindicativo e tem o 'povo' como protagonista principal, o que a torna um processo democrático e educativo. É um instrumento político das classes subalternas para externar sua concepção de mundo, seu anseio e compromisso na construção de uma sociedade igualitária e socialmente justa. (PERUZZO, 2009, p. 49-50 - grifos da autora).

Embora possamos perceber as similaridades existentes entre as definições, compreendê-las como sinônimos é, como afirma Miani (2006), um caminho simplificado e reducionista para conceber conceitos que carregam expressões ideológicas tão importantes para os processos comunicativos. Em relação à comunicação popular e à comunicação comunitária, Miani (2006) considera incompatível a compreensão destes termos como sinônimos. Para este autor, a comunicação comunitária está relacionada ao conceito de comunidade e a comunicação popular ao antagonismo de classes e, portanto, não podem ser confundidos. Em relação às considerações apontadas por Peruzzo (2009) e Miani (2006) nos questionamos:

(1) A comunicação popular é feita para o povo e/ou para e com o povo?

Comun. \& Inf., v. 15, n. 2, p. 34-52, jul./dez. 2012 
(2) A comunicação alternativa representa outro tipo de abordagem ou ela é uma comunicação local, que atende à interesses específicos e, por isso, alternativa aos meios de comunicação massivos?

(3) As formas de comunicação popular e alternativa são encontradas somente em veículos comunitários? E o que significa ser comunitário, principalmente para aqueles que podem participar desse fenômeno comunicacional?

Não pretendemos aqui, responder de imediato a essas questões, já que, além de não termos as respostas, estas demandam um percurso de reflexão e de amadurecimento teórico para a comunicação comunitária. Entretanto, ao partirmos da comunicação comunitária como um processo mais amplo, consideramos, de acordo com Peruzzo (2009), que, uma comunicação popular nem sempre é comunitária, mas uma comunicação comunitária sempre é popular. Ora, se os meios comerciais produzem produtos midiáticos dirigidos ao povo, podemos dizer que realizam uma comunicação popular com o intuito de captar e aumentar sua audiência. Seus objetivos centram-se em disputas mercadológicas. Já as mídias comunitárias, formadas por associações comunitárias sem fins lucrativos, sustentam-se com escopos diferenciados. A comunicação popular nessas mídias vê o povo como um público capaz de transformar o seu entorno social, dotado de capacidades emancipatórias e cidadãs que se mobiliza e se desenvolve enquanto ator social. Sendo assim, consideramos, de antemão, que a comunicação comunitária é um fenômeno comunicativo que atinge esferas mercadológicas e não mercadológicas. A produção de conteúdo de cunho popular não se restringe às emissoras comunitárias.

Percebemos, assim, que nas rádios comunitárias, a comunicação comunitária, considerada como um macroprocesso que abarca as comunicações popular e alternativa acolhe práticas comunicativas feitas pelo povo e para o povo como um meio de comunicação capaz de mobilizar os sujeitos para suas demandas locais e, dessa forma, representa uma gama de alternativas de produção de conteúdo na comunidade em que se insere (Gráfico 1).

Gráfico 1 - comunicações comunitária, alternativa e popular

Comun. \& Inf., v. 15, n. 2, p. 34-52, jul./dez. 2012 


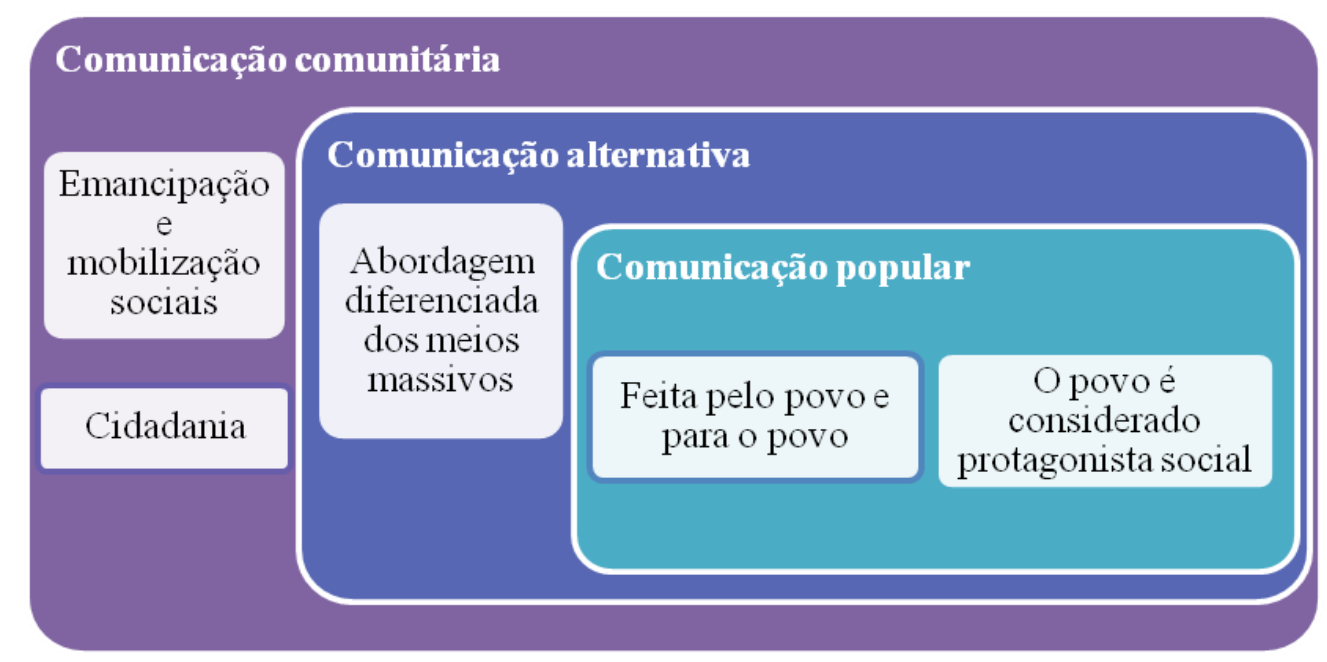

Fonte: elaboração própria.

Assim, entendemos que, a priori, a comunicação para e nas rádios comunitárias é comunitária entendida aqui como a "expressão de lutas populares por melhores condições de vida que ocorrem a partir dos movimentos populares e representam um espaço para a participação democrática do "povo" (PERUZZO, 2006, p. 4 - grifos da autora). De qualquer forma, oferecer uma proposta conceitual irá depender das experiências de comunicação presentes nas rádios em estudo. Nesse sentido, apresentamos sua relação com o conceito de comunidade como pressuposto teórico para o desenvolvimento do conceito de comunicação comunitária.

Segundo Paiva e Sodré (2004), as mídias comunitárias surgem de um propósito gerado pelas demandas sociais da comunidade em busca de um lugar político na sociedade. Sua motivação reside no descontentamento coletivo com o conteúdo produzido pelos meios de comunicação comerciais. Por isso, as rádios comunitárias possuem características norteadoras bastante nítidas - a aproximação e o vínculo com o espaço físico e simbólico da comunidade - além da possibilidade de produção de conteúdos com informações locais, favorecendo a realização de uma programação alternativa. Pode, ainda, realizar campanhas, eventos, oficinas e demais intervenções baseadas nas carências sociais, culturais e educativas da comunidade. Há, nesses meios comunitários, uma riqueza de potenciais emancipatórios que decorre de sua capacidade de criar estratégias para a mobilização social que, ao envolverem os sujeitos no processo de corresponsabilidade, sentem-se empoderados social e comunicativamente a realizar projetos político-emancipatórios.

A partir disso, Paiva (2007) propõe uma releitura do conceito de comunidade desenvolvido por Ferdinand Tönnies e nos apresenta o conceito de comunidade gerativa. Esse conceito resgata a

Comun. \& Inf., v. 15, n. 2, p. 34-52, jul./dez. 2012 
vinculação social por meio da proximidade territorial dos sujeitos, a preocupação com o patrimônio cultural e a busca pela sociabilidade. A comunidade gerativa é, então, conceituada como

[...] o conjunto de ações (norteadas pelo propósito do bem comum) passíveis de serem executadas por um grupo e/ou conjunto de cidadãos. A proposição parte da evidência de que o horizonte que caracteriza a sociedade contemporânea - a falência da "política de projetos", a descentralização do poder, a forte tônica individualista e cosmopolita, além da excessiva presença da violência nas relações sociais - produz a busca de alternativas (PAIVA, 2003, p. 5-6).

Dentre essas alternativas estão as rádios comunitárias como um projeto político e comunicacional na construção de uma sociedade em que os sujeitos tornem-se, através da mobilização social, elos de emancipação para a democratização da comunicação. O conceito de comunidade gerativa é desta forma, compreendido no âmbito das rádios comunitárias por assumir uma perspectiva direcionada para o fortalecimento dos laços comunitários e, portanto, dos vínculos que se baseiam no espaço da comunidade. É um conceito que sugere que uma coletividade se mobilize para atuar de forma conjunta em relação aos seus interesses comuns. As mídias comunitárias, tal como o rádio, são potenciais lócus de fomentação de comunidades gerativas. Organizam-se, desenvolvem-se e, principalmente, mobilizam-se para promover a emancipação social das comunidades em que vivem.

\section{Renovar o olhar sobre a mídia e reinventar as rádios comunitárias}

De maneira análoga à obra de Santos (2007), intitulada Renovar a teoria crítica e reinventar a emancipação social, nos propusemos nesta seção a renovar o olhar sobre a mídia e reinventar as rádios comunitárias. O intuito de reinventá-las é pensar de que modo as rádios comunitárias podem constituir-se como estratégia para a mobilização social.

O fenômeno das rádios comunitárias, bem como as rádios livres, adquire sentido quando colocado no contexto das lutas por emancipação social (GUATTARI, 1987). Expressam a vontade do cidadão de reinventar novas formas de comunicação e de se relacionar com os sujeitos que compartilham de um mesmo propósito mobilizador. São parte de um projeto político que busca trazer para si as causas sociais e formas de enfrentamento. Buscam captar e envolver os sujeitos que, devido à falta de informação e de conhecimento sobre seus direitos de cidadania são excluídos dos processos de mobilização social. Como um espaço social, podem construir seus próprios discursos ao incluir minorias marginalizadas e desamparadas em suas lutas por reconhecimento e igualdade. As minorias são entendidas, conforme Sodré (2005) como setores sociais comprometidos

Comun. \& Inf., v. 15, n. 2, p. 34-52, jul./dez. 2012 
com a questão social. Esses setores se caracterizam por sua luta por reconhecimento e pela mobilização em torno de suas causas. Carregam em si o impulso da transformação em busca de mudanças nas relações de poder preestabelecidas. O campo conflituoso em que se situam as minorias define-se como um lugar simbólico onde habitam a igualdade e a diferença. $\mathrm{O}$ conceito contemporâneo de minoria diz respeito à oportunidade de dar voz aos grupos sociaisminoritários e abertura política nos processos decisórios que as envolvam.

Neste contexto, ressaltamos a ausência de espaços democráticos para a expressão das minorias nos meios de comunicação hegemônicos. Como afirmam Carpentier, Lie e Servaes (2001), a mídia pode ser entendida, na visão relacionista, como uma alternativa aos meios de comunicação hegemônicos, constituindo-se uma mídia alternativa, como as rádios comunitárias. Deste modo, para refletirmos sobre de que forma as rádios comunitárias podem constituir-se como estratégia para a mobilização social, além de acionar os conceitos de mídia alternativa e comunicação comunitária, faz-se necessário sua relação com a teoria das epistemologias do sul (SANTOS, 2007; 2009). Apresentaremos a seguir os conceitos fundantes desta teoria e sua relação com o objeto de estudo em questão.

Através da metáfora do norte e do sul - ambas categorias geográficas - Santos (2009), traz uma proposta de desconstrução da constituição do pensamento e das relações sociais. Como uma forma de descolonização dos atores sociais das amarras do pensamento hegemônico (norte), o autor clarifica nossas percepções para outras formas de compreender o mundo (sul). Sua proposição sustenta que o formato colonial ainda permanece vigente nas formas de estruturar o conhecimento e nas práticas sociais. Por isso, Santos (2009) defende que para haver justiça social, deve haver, também, justiça cognitiva, ou seja, a construção de um pensamento pós-abissal.

"O pensamento pós-abissal parte da ideia de que a diversidade do mundo é inesgotável e que esta diversidade continua desprovida de uma epistemologia adequada. Por outras palavras, a diversidade epistemológica do mundo continua por construir" (SANTOS, 2009, p. 43).

A racionalidade dominante que limita e reduz as possibilidades de conhecimento, imobiliza os avanços democráticos e plurais é chamada pelo autor de razão indolente. Esta pode ser considerada sob dois aspectos. A primeira é a razão metonímica, no qual se reduz o presente, ao não possibilitar sua visão ampla. A segunda é a razão proléptica, em que o futuro se expande e o futuro se contrai; assim, abre espaços para inclusão de conhecimentos e experiências para preparar o futuro. 
Para dar consistência à epistemologia do sul, o autor apresenta-nos o conceito de ecologia de saberes e sociologia das emergências para dar suporte à manifestação de pensamentos múltiplos e contra hegemônicos. Na concepção da ecologia dos saberes, são valorizados os conhecimentos informais, ditos não científicos. De forma consoante com o pensamento do autor, reconhecemos a credibilidade dos saberes que provém das experiências e aprendizados dos atores sociais. A ecologia dos saberes é uma forma de explorar a pluralidade desses saberes e torná-los visíveis através de meios de comunicação comunitários uma vez que "[...] deve-se dar preferência às formas de conhecimento que garantam a maior participação dos grupos sociais envolvidos na concepção, na execução, no controlo e na fruição da intervenção" (SANTOS, 2009, p. 51).

O conceito de sociologia das emergências surge em sua teoria em contraposição à sociologia das ausências. Esta é um procedimento que mantém na superfície o pensamento hegemônico e nas profundezas a diversidade de conhecimentos existentes. É uma forma de apagamento da pluralidade que faz permanecerem visíveis as monoculturas produzidas pela racionalidade ocidental. São cinco formas de produção das ausências (monoculturas) perpassadas por relações de poder simbólicas e hierárquicas: monoculturas do saber e do rigor; do tempo linear; da naturalização das diferenças; da escala dominante e do produtivismo capitalista. Em substituição às monoculturas, Santos (2007), propõem, em contrapartida, formas de emergir o que está ausente: ecologias dos saberes; das temporalidades; do reconhecimento; da transescala e das produtividades.

Acredita-se que "os novos modos de produção do conhecimento exigem outros espaços" (SANTOS, 2007, p. 46). Destarte, propomos uma aproximação entre as ecologias e as rádios comunitárias (tabela 2) com o escopo de pensar as rádios comunitárias como uma estratégia para a mobilização social e articulá-la à comunidade local como parte de um processo de tradução que envolve novas formas de relacionar conhecimentos e de reconhecer a diversidade.

Propomos-nos a reinventar possibilidades emancipatórias por meio das ecologias com o intuito de fazer emergir os silenciamentos e os discursos contra hegemônicos que não se fazem presentes nas monoculturas. Confrontamos o pensamento dominante do saber e do rigor que considera apenas os conhecimentos científicos; a existência de um tempo linear, marcado por relações capitalistas neoliberais; da exclusão e naturalização daquilo que não corresponde aos formatos estandardizados; ao universalismo e à globalização; e a produtividade mensurada pela lucratividade. As ecologias nas rádios comunitárias constituem-se, assim, como uma estratégia para dar voz à sociologia das emergências e a reelaborar o processo democrático dentro de uma perspectiva de tradução cultural.

Comun. \& Inf., v. 15, n. 2, p. 34-52, jul./dez. 2012 
Tabela 2 - Epistemologias do Sul e Rádios Comunitárias

Comun. \& Inf., v. 15, n. 2, p. 34-52, jul./dez. 2012 


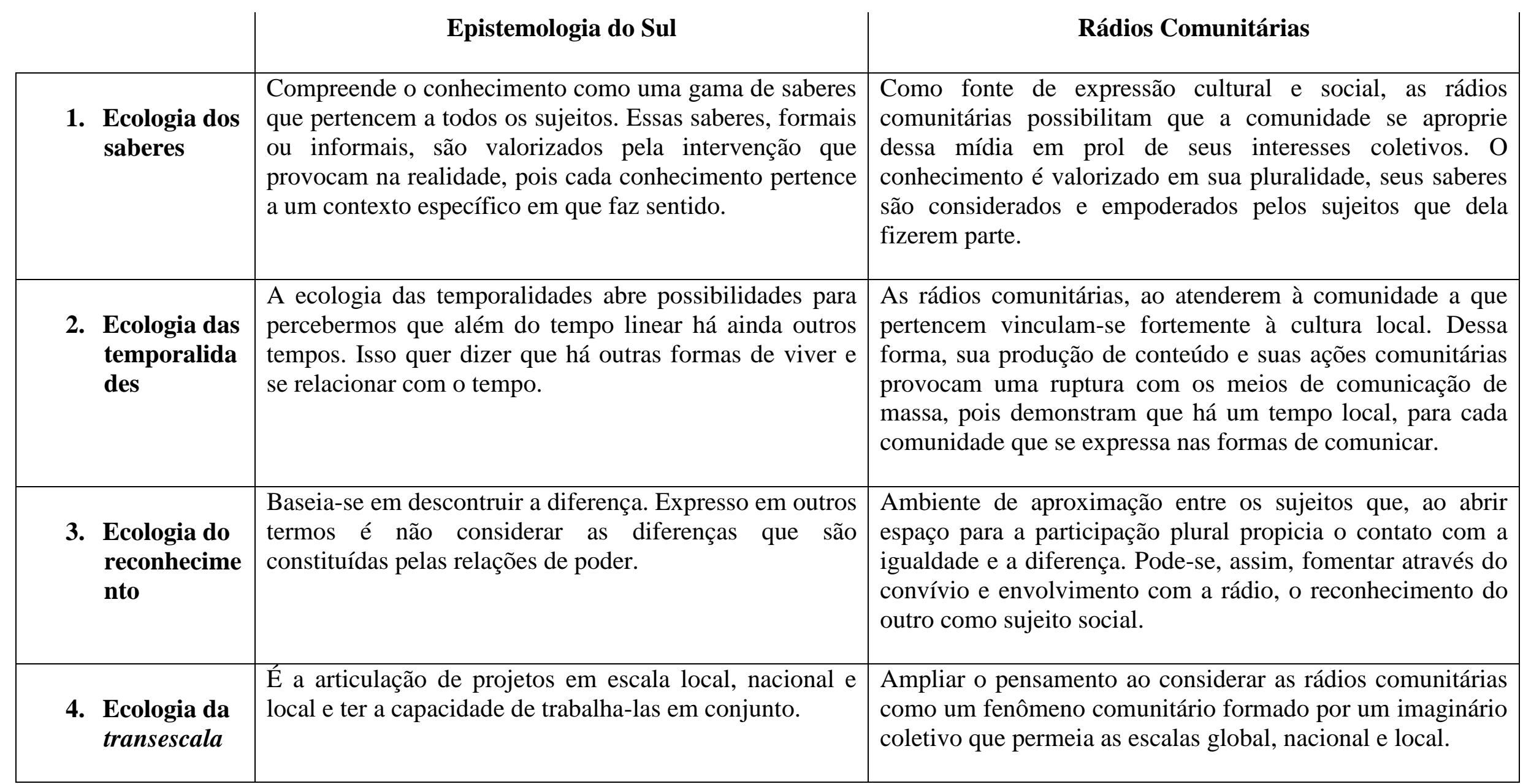


5. Valoriza os sistemas alternativos de produção, como as 5. Ecologia das organizações populares, as cooperativas, as associações produtivida des comunitárias etc. e cria uma nova lógica que recupera as culturas locais e as formas solidárias de produção.
A constituição e a estruturação das mídias comunitárias valorizam a comunidade e suas formas alternativas e populares de exercer o direito à comunicação. Surgem ecologias para as formas de produção, disseminação e consumo de conteúdos midiáticos que independem de saberem institucionalizados.

Fonte: elaboração própria. 


\section{Análise empírica}

Para compreendermos de que forma as rádios comunitárias se aproximam das ecologias de Santos (2007), propomos neste trabalho trazer a experiência comunicativa e cidadã de uma das quatro rádios comunitárias localizadas na cidade de Santa Maria (RS). Salientamos que, a referida análise empírica, possui, para fins deste trabalho, caráter exemplificativo.

As informações para verificação e análise foram coletadas por meio de entrevista semiestruturada contendo questões abertas e realizada com um representante ${ }^{3}$ do conselho comunitário desta rádio. Com base nessas informações é que descreveremos a situação atual da rádio e apresentamos nossas aproximações teórico-empíricas.

As questões para a entrevista foram formuladas com o intuito de representar, no contexto das rádios comunitárias, as cinco ecologias que compõe a teoria da epistemologia do sul: ecologia dos saberes, ecologia das temporalidades, ecologia do reconhecimento, ecologia da transescala e ecologia das produtividades. Entendemos que há inúmeras formas de interpretar e compreender como as ecologias podem ser visualizados em uma mídia comunitária. Entretanto, recorremos às questões que nos dessem respaldo para refletirmos sobre as possíveis aproximações entre as rádios comunitárias e as ecologias. Portanto, a ecologia dos saberes contempla questões sobre a programação e a escolha das temáticas dos programas; a ecologia das temporalidades investiga como é a relação da rádio com a comunidade e com a cultura local; a ecologia do reconhecimento questiona quem pode participar da rádio; a ecologia da transescala refere-se ao movimento pela democratização da comunicação em níveis local, nacional e global; e, por fim, a ecologia das produtividades reporta-se às formas de produção de conteúdo e outras ações de cunho comunitário (eventos, palestras, oficinas etc.).

A rádio comunitária Cidadania $F M^{4}$ está localizada no bairro Nova Santa Marta, na cidade de Santa Maria (RS). Possui pedido de autorização para funcionamento desde 2008 e, até este ano (2012), continua em processo de regularização. Durante esses quatro anos de processo surgiu outra rádio comunitária no mesmo bairro. Esta rádio disputa seu espaço com a Rádio Comunitária Cidadania $F M$, na qual centraremos nossa reflexão. A partir desta conjuntura, já podemos apontar limitações por parte do Ministério das Comunicações (MiniCom) no que tange à democratização da

\footnotetext{
${ }^{3}$ A rádio comunitária analisada neste trabalho encontra-se em processo de regularização. Por isso, optamos por manter a confidencialidade de sua identidade e utilizar um nome fictício para a rádio.

${ }^{4}$ Nome fictício para a rádio comunitária.
}

Comun. \& Inf., v. 15, n. 2, p. 34-52, jul./dez. 2012 
comunicação. As rádios comunitárias possuem o papel de atender à comunidade local e, de acordo com a legislação, devem ter o alcance máximo de um quilômetro da antena transmissora. Isso quer dizer que podemos ter várias rádios comunitárias em um mesmo bairro, já que essas mídias possuem alcance restrito e uma demanda local específica. Cabe ao Ministério das Comunicações agilizar os processos de regularização, permitir a atuação de ambas as rádios e, assim, reconhecer o direito à comunicação para fazê-lo valer na prática.

Por encontrar-se em processo de regularização, a rádio não pode exercer seu direito à comunicação como as rádios comunitárias autorizadas o fazem. Seu funcionamento limita-se aos finais de semana, visto que, o MiniCom pode penalizá-la com apreensões de equipamentos, processos judiciais e, até com o fechamento da emissora. Segundo o entrevistado ${ }^{5}$ - representante do conselho comunitário da rádio -ela continua em funcionamento "porque a comunidade precisa de um meio de comunicação comunitário”.

De acordo com as informações coletadas acerca da ecologia dos saberes, a rádio comunitária possui uma programação plural e, ao mesmo tempo sazonal. A programação é considerada plural por apresentar múltiplos atores sociais, pertencentes a diferentes segmentos da sociedade. Foi relatado pelo entrevistado a participação da Escola Marista Santa Marta, das associações comunitárias do bairro e do Movimento Nacional de Luta pela Moradia (MNLM). Além disso, a mídia comunitária é um veículo de comunicação aberto a toda comunidade, que possui temáticas variadas, a depender do seu interesse. Percebe-se que a mobilização dos atores sociais em torno da rádio é limitada devido a sua situação de não regularização perante o MiniCom.

Na ecologia das temporalidades, depreendemos que a rádio possui uma relação próxima com a comunidade local, rompendo com os padrões lineares de relação com o tempo. Há, na relação entre a rádio e a comunidade, a valorização dos vínculos comunitários pelo reconhecimento de um tempo local, em que se respeitam as especificidades de cada grupo social e que se manifestam no espaço da rádio. Dessa forma, os conteúdos veiculados na programação são reelaborados de acordo com os interesses coletivos da comunidade, no qual são adequadas suas mensagem e linguagem. Outra forma de valorização da comunidade local é a interatividade proporcionada pelo envio de mensagens via celular para a rádio. $\mathrm{O}$ público pode enviar sugestões musicais e mensagens a serem divulgadas. Através das diferentes formas de valorizar a comunidade local, pode-se perceber a dissolução do tempo da globalização capitalista em que imperam a lógica

${ }^{5} \mathrm{O}$ nome do entrevistado será mantido em sigilo.

Comun. \& Inf., v. 15, n. 2, p. 34-52, jul./dez. 2012 
do individualismo e do consumo para um tempo que prioriza as experiências cotidianas dos sujeitos, suas demandas locais e, principalmente, sua luta por espaços de cidadania. "Isso vai criar outra maneira de entender, outra maneira de articular conhecimentos, práticas, ações coletivas, de articular sujeitos coletivos" (SANTOS, 2007, p. 39).

A ecologia do reconhecimento reflete-senas formas de participação dos atores sociais na rádio. A diretoria fundadora é formada por representantes das Aldeias Infantis $\mathrm{SOS}^{6}$, pelo MNLM, pela Escola Marista, por associações comunitárias, pelas igrejas católica e evangélica e pelo presidente, morador do bairro em que a rádio está localizada. Contam ainda, com o apoio do Projeto Alquimia $^{7}$, do Ministério Público do Rio Grande do Sul. A programação, como citado anteriormente, é expressa pela pluralidade daqueles que se empenham pela mobilização de suas vozes em prol da comunidade. Atualmente, a rádio comunitária possui programas que aliam música e informação local, como o Nossa terra, Nossa gente, Nossa música transmitido ao vivo, aos domingos. A abertura da rádio para a participação de variados segmentos da comunidade fomenta espaços em que há o reconhecimento do outro como um sujeito de igualdade/diferença. A troca de experiências e a mobilização gerada por um mesmo ideal provoca o sentimento de coletivização e de respeito a diferentes formas de expressão cultural, social e comunicativa visto que a rádio é um espaço de pluralidade que deve ser partilhado entre todos. Como aponta a lei $9612 / 98^{8}$, uma rádio comunitária deve respeitar valores éticos e sociais, além de favorecer a integração dos membros da comunidade. Acrescentamos a isso, o reconhecimento da igualdade/diferente entre os atores desta comunidade.

O movimento pela democratização da comunicação apresenta-se em níveis local, nacional e global, através de meios de comunicação comunitários como as rádios. Diante disso, a ecologia da transescala nos desafia a pensar a articulação dessas esferas e trabalha-las conjuntamente. Esta pode ser também uma alternativa para o fortalecimento do movimento e pelo reconhecimento dos direitos de cidadania já que da articulação desses níveis emerge a consciência de fazer parte de uma

\footnotetext{
${ }^{6}$ As Aldeias Infantis SOS Brasil apoiam crianças e famílias em situação de vulnerabilidade desenvolvendo projetos nas áreas de "Fortalecimento Familiar e Comunitário", "Acolhimento" e "Advocacy". Mais informações em: <http://www.aldeiasinfantis.org.br>.

${ }^{7} \mathrm{O}$ principal objetivo do projeto é dar um destino ambiental adequado às máquinas caça-níqueis apreendidas pelo MPRS, reaproveitando seus componentes. Através do Programa Socioambiental de Recondicionamento e Reciclagem, jovens em situação de vulnerabilidade social, dependentes químicos em fase de reabilitação e apenados participam deste programa como um meio de inclusão social. Informações disponíveis em: < http://www.mp.rs.gov.br/alquimia> Acesso em: 09 dez. 2012.

${ }^{8}$ Disponível em: < http://www.planalto.gov.br/ccivil_03/leis/L9612.htm> Acesso em: 07 dez. 2012.
}

Comun. \& Inf., v. 15, n. 2, p. 34-52, jul./dez. 2012 
totalidade coletiva e mobilizada socialmente. No que tange à regulamentação do serviço de radiodifusão comunitária, o entrevistado reivindicou a municipalização da lei 9612/98 e a articulação entre os governos federal, estadual e municipal para realizarem parcerias com as rádios comunitárias. A municipalização seria uma forma de reduzir a burocratização que sofrem as rádios comunitárias para obter a outorga de funcionamento. As parcerias seriam uma forma de comunicação dirigida entre o governo e os cidadãos tendo em vista o caráter local de uma rádio comunitária.

As formas de produção de conteúdo na rádio manifestam-se através da ecologia das produtividades. Segundo o entrevistado, a rádio ainda não produz notícias com a comunidade devido à inexistência de outorga por parte do MiniCom. Todavia, produzem notícias de interesse local para a comunidade, evitando a reprodução dos padrões das rádios comerciais. Para o entrevistado, uma mídia comunitária não deve ser feita por profissionais, mas sim por atores sociais da comunidade.

O tratamento dado à informação é diferenciado devido à valorização dos saberes locais e à ênfase concedida aos problemas sociais enfrentados pela comunidade. Conforme o entrevistado, as reivindicações e discussões em torno desses problemas dificilmente possuem espaço como pauta dos veículos de cunho mercadológico. A rádio comunitária é, assim, o lócus para a concretização de processos de produção alternativos aos meios de comunicação hegemônicos. Por isso, destacamos a importância das rádios comunitárias como um fenômeno social que se constitui no movimento pela democratização da comunicação como uma luta política e emancipatória para o exercício da cidadania.

\section{Apontamentos finais}

A problemática empreendida neste trabalho considerou a comunicação como uma instância de poder, permeada pelas intencionalidades dos sujeitos envolvidos. Com referência aos processos de democracia e emancipação social, acionamos um referencial teórico que pudesse dar conta dos desafios teóricos que as rádios comunitárias demandam. Diante disso, nosso intuito foi apurar os conceitos de mídia alternativa, comunicação comunitária e seus desdobramentos. Num segundo momento, buscamos aproximar a teoria da epistemologia do sul da perspectiva das rádios comunitárias numa tentativa de realoca-la como um fenômeno comunitário constituinte do processo de tradução cultural. Reportamos-nos, então, às ecologias dos saberes, das temporalidades, do

Comun. \& Inf., v. 15, n. 2, p. 34-52, jul./dez. 2012 
reconhecimento, da transescala e das produtividades para promover a renovação do olhar sobre a mídia e reinventar as rádios comunitárias.

Compreendemos esse processo como a inclusão das minorias em um espaço de pluralidade em que se podem desenvolver formas democráticas de comunicação e cidadania. São formas de confrontar os novos formatos de apartheid social existentes atualmente. As rádios comunitárias podem ser consideradas, portanto, como um meio que atende à comunidade, é alternativo aos meios de comunicação hegemônicos, é parte da sociedade civil e é rizomática. A ênfase em uma dessas abordagens irá depender do contexto social, político, econômico e cultural em que a rádio está inserida.

Não pretendemos - vale salientar - encerrar as perspectivas e possibilidades que se manifestam nesta reflexão, visto que, reconhecemos suas limitações teórico-empíricas. Por isso, destacamos que o caso ilustrativo foi realizado com base na qualificação que atribuímos às rádios comunitárias. Isso significa que, “[...] se o conceito não é uma entidade absoluta acerca de algo a ser alcançado e incorporado, se não representa uma verdade universal que independe do contexto (plano de imanência), devemos utilizá-lo como ferramenta para pensar e produzir novos conceitos" (KHOURI, 2009). As qualificações das rádios comunitárias são, assim, pistas que podem se conectar a outras para serem reapropriadas e redefinidas a depender do contexto em que se inserem. De igual modo, a relação entre os conceitos que representam um ideal de rádios comunitárias e sua aplicação prática não estão em um perímetro hermético, mas apresentam uma possibilidade de tensionamento teórico-prático para pensarmos a comunicação.

Assim, a análise empírica da Rádio Comunitária Cidadania FM demonstrou que esta mídia alternativa se encaixa na abordagem teórica que atende à comunidade e sua relação aproximativa com as ecologias propiciou um novo tipo de racionalidade, baseada nos princípios de cidadania. Inferimos que a partir dessa aproximação podemos reelaborar estratégias para a mobilização social e, assim, fomentar mecanismos de emancipação dos atores sociais. Desenvolve-se, por conseguinte, subjetividades rebeldes e motivadas pelo climanen que envolve os movimentos pela democracia e as lutas pelos direitos de cidadania.

Artigo submetido em 09/12/2012 e aceito em 14/03/2013.

Comun. \& Inf., v. 15, n. 2, p. 34-52, jul./dez. 2012 


\section{Referências}

CARPENTIER, N.; LIE, R.; SERVAES, N. Community media: muting the democratic media discourse? Brighton: Koccc Centre for Critical Studies in Communication and culture, 2001.

MACHADO, Arlindo; MAGRI, Caio; MASAGRÃO, Marcelo. As rádios livres em direção a uma era pós-mídia. In: Rádio livres: a reforma agrária no ar. Prefácio de F. Guattari. 2. ed. São Paulo: Editora Brasiliense, 1987. p. 9-13.

KHOURI, M. M. E. Rizoma e educação: contribuições de Deleuze e Guattari. In: ENCONTRO NACIONAL DA ASSOCIAÇÃO BRASILEIRA DE PSICOLOGIA SOCIAL, 15., 2009, Maceió. Anais... Maceió: ABRAPSO, 2009.

MIANI, R. A. Comunicação comunitária: uma alternativa política ao monopólio midiático. In: ENCONTRO DA ULEPICC-BRASIL, 1., 2006, Niterói. Anais... Niterói: Uleppic, 2006.

PAIVA, R. Política de minorias: comunidade e cidadania. Estudos em

Comunicação/Communication Studies, Covilhã, v. 1, p. 1-7, 2003. Disponível em: <http://www .labcom.ubi.pt/files/agoranet/03/paiva-raquel-politica-de-minorias.pdf>. Acesso em: 22 nov. 2012.

PAIVA, R.; SODRÉ, M.. O sequestro da fala Comunitária. InterSciencePlace, Rio de Janeiro, p. 35-46, 2004. Disponível em: 〈http://www.interscienceplace.org/interscienceplace/article/view/3/5>. Acesso em: 22 nov. 2012.

PERUZZO, C. K. Conceito de comunicação popular, alternativa e comunitária revisitados e reelaborações no setor. ECO-Pós, Rio de Janeiro, v. 12, n. 2, p. 46-61, maio/ago. 2009.

A comunicação no desenvolvimento comunitário e local, com cibercultur@. In: COMPÓS, 21., 2012, Juiz de Fora.

Revisitando os conceitos de comunicação popular, alternativa e comunitária. In: CONGRESSO BRASILEIRO DE CIÊNCIAS DA COMUNICAÇÃO, 29., 2006, Brasília/DF.

SANTOS, B. S. Epistemologias do Sul. São Paulo: Cortez, 2010. p. 15-83.

Renovar a teoria crítica e reinventar a emancipação social. São Paulo: Boitempo Editorial, 2007.

SODRÉ, M. Por um conceito de minoria. In: BARBALHO, Alexandre; PAIVA, Raquel (Org.). Comunicação e cultura das minorias. São Paulo: Paulus, 2005. p. 11-14. 